\title{
Soziale Muskelrelaxation nach Höcke, Wilders, Le Pen
}

\section{Frank Fischer}

Dr. med., Facharzt für Psychiatrie und Psychotherapie, Mitglied FMH

Menschen und Spannung - das ist ein heikles Thema. Ein bisschen Spannung lieben wir. Denn das regt an und hält kreativ. Aber zu viel davon: nein danke. Wenn zu viel los ist, uns zu viele ungelöste Themen gleichzeitig beschäftigen, wenn zentrale Bedürfnisse ungestillt bleiben und wir nicht wissen, wie weiter, dann lässt das Kribbeln im Bauch nicht lange auf sich warten: Spannungen werden körperlich spürbar - als Schwitzen, Herzklopfen, Bauchkribbeln oder Zittern. Was der Steinzeitmensch noch kämpfend oder flüchtend abbauen konnte, müssen wir heute auf dem Bürostuhl aussitzen. Wie bauen wir heutigen Menschen Spannung ab? Bewegung tut noch immer gut, mit Joggingschuhen, Velo oder - nach der Lehre der progressiven Muskelentspannung nach Jacobson - indem wir auf einer Decke liegend die Muskeln anspannen und wieder loslassen und das damit verbundene Entspannungsgefühl in uns aufnehmen.

Auch viele psychische Krankheiten dienen der Spannungsreduktion, wenn auch nur kurzfristig: Ängstliche Anspannung kann sich in Panikattacken steigern und entladen; Depressionen verlangsamen in einer spannungsreichen Situation; anorektisches Hungern gibt Kontrolle über den Körper und das Gefühl, so auch den Rest wieder im Griff zu haben; Bulimie führt Spannung über Erbrechen ab und Borderline-Patientinnen reduzieren ihre innere Anspannung durch Selbstverletzungen. Viele Spannungslöser sind nur kurzfristig wirksam: Betäuben mit Alkohol und Drogen, Weinen, Klagen, mit dem Finger auf andere zeigen. Je unreifer die Persönlichkeit, desto mehr greift sie auf gedankliche Ausgrenzung zurück: Störende Gedanken werden vermieden, verdrängt, abgespalten. Kurzfristig nimmt auch hier die innere Spannung ab. Je reifer die Persönlichkeit, desto besser kann sie Spannung aushalten und querstehende, stossende Einsichten ertragen und integrieren. Spannung kommt nicht nur beim Einzelnen, sondern auch in sozialen Gruppen vor. Ihre Höhe hängt dabei von der Unterschiedlichkeit der Teilnehmer und der Versorgungslage ab. Je homogener eine Gruppe ist, desto weniger Spannung ist vorhanden, aber desto langweiliger ist sie auch. In einer materiell satten Gesellschaft bedeutet das Andersartige willkommene Abwechslung. Wenn aber knapp wird, was wir zum Leben brauchen, steigt die
Spannung im System - und plötzlich verträgt es keine Andersartigkeit mehr. Dann machen harmlose Bärte Angst und die Burka wird verboten. Die Spannung entlädt sich durch soziale Ausgrenzung. Ist das Fremde weg, ist das System wieder homogener und damit weniger spannungsgeladen, aber auch weniger spannend. Das ist kein exklusives Problem rechter Populisten. Es ist zutiefst menschlich, dass wir in Knappheit und Krise rigide reagieren, dem Neuen kritisch und abwehrend gegenüberstehen, in frühbewährte Muster zurückfallen und komplexe "Problemknoten» mit einfachen Lösungen durchhauen wollen. Wenn sich also eine alteingesessene Zürcher Dame im Stadtteil ihrer Kindheit verlaufen hat und um sich herum nur noch fremd klingende Sprachen hört, dann darf sie sich unwohl fühlen, ohne dass man sie dafür diffamieren muss. Denn fremde Klänge können überfordern und stressen. Andererseits können sie aber auch inspirieren und beflügeln, je nachdem wie gut es uns geht. Jeder Mensch ist anders in seiner Fähigkeit, mit Unterschiedlichkeiten zu leben. Je sicherer wir uns in unserem Leben fühlen dürfen, desto höher ist unsere Fähigkeit, Andersartiges und Fremdes willkommen zu heissen.

Der Rechtspopulismus will die Spannung im System reduzieren, indem er alles Fremde in die Wüste jagt. Wenn wir dem etwas entgegensetzen wollen, dann müssen wir die soziale Sicherheit im Auge behalten: Denn die Bereitschaft, Andersartigkeit zu integrieren, nimmt ab, wenn Löhne so niedrig sind, dass sie einen nicht mehr ernähren; wenn Arbeitsplätze so unsicher sind, dass man sie jederzeit verlieren kann; wenn das Gefühl verloren geht, politisch etwas bewirken zu können, weil man, wie in Deutschland, nur alle vier Jahre die Wahl zwischen leicht verwechselbaren Parteien hat. Es mag sein, dass niedrige Löhne und ein geringer Kündigungsschutz für Beschäftigung sorgen. Wenn dafür aber soziale Spannungen und mit ihnen Rassismus und Ausgrenzung zunehmen, dann ist wenig gewonnen. Und sicher, Multikulti ist ein schönes Ideal, aber die menschliche Realität setzt auch hier Grenzen. Die Gegenstrategie zu Höcke, Wilders und Le Pen liegt jenseits von links und rechts; sie heisst ganz einfach «sozialer Friede» - wenn wir den erhalten können, dann sind wir den Extremen gegenüber weniger anfällig. 